\title{
RETRACTED ARTICLE: A method to assign sex to leopard Panthera pardus specimens using quantitative cranial data
}

\author{
Igor Khorozyan
}

Received: 25 August 2013/Revised: 21 November 2013/Accepted: 27 November 2013/Published online: 5 January 2014 (C) Springer-Verlag Berlin Heidelberg 2014

This article has been retracted at the request of the Editorin-Chief. It was established that the author of this article did not have permission to use part of the data and therefore had no right to publish.

I. Khorozyan ( $\square)$

Workgroup on Endangered Species, Johann-Friedrich-

Blumenbach Institute of Zoology, University of Göttingen,

Bürgerstrasse 50, 37073 Göttingen, Germany

e-mail: igor.khorozyan@biologie.uni-goettingen.de 